\title{
STRATEGI ALIANSI \\ DALAM MENGHADAPI GLOBALISASI (STUDY PADA PERUSAHAAN FURNITURE DI KABUPATEN JEPARA)
}

\author{
Apriyanti \\ Email : kelip.apriyanti94@gmail.com
}

\begin{abstract}
Abstrak : The problem that is faced by furniture entrepreneur at Jepara is limitation of production capacity and limitation of design that have had. So produce can't fulfi the buyer demand in at a certain time. This case can be anticipated by make an alliance strategy between several companies, where this solution is main alternative to face the problem. This strategy model was proposed by Michael Yoshino and Rosabeth Kanter where alliance strategy can be happen in various form, which in fact it is a base form marketing alliance that, enclose: product or sevice alliance, promotional alliance, logistic alliance and pricing collaborations. This examination intend to give alternative of formulation strategi that will be used by company in make alliance strategy.To reach the purpose in order to get exact strategy formulation is used by analisis tool that are SWOT Matric, BCG Matric, and QSP Matric. With first base by identifying external factor and internal factors. The result of alliance strategy analysis formulation at furniture company according analysis result of SWOT Matric, BCG Matric, and QSP Matric are recommended 4 strategy that is done by each company with step priority application as follow: I Strategic service alliance, II Strategic opportunity alliance, III Strategic pricing collaboration and IV Strategic promotional alliance.
\end{abstract}

Kata kunci : Strategi, Aliansi, Globalisasi

\section{PENDAHULUAN}

Dinamika globalisasi \& revolusi teknologi yang sedang melanda dunia saat ini, sudah dapat dipastikan akan mempengaruhi peta dan pola persaingan dunia bisnis secara drastis. Telah banyak bukti menunjukkan bahwa sangatlah sulit untuk dapat berhasil dalam menguasai pasar dengan kekuatan sendiri. Strategifight' em or join' em (kita lawan atau kita bergabung) masih sering diterapkan. Dalam satu sisi "melawan" akan terlihat lebih berani, tetapi dengan konsekuensi dapat menang atau hancur. Sedangkan dengan bergabung akan dirasakan adanya kehilangan kontrol. Dari dasar inilah strategi aliansi tercipta, dimana kedua elemen strategi tadi dapat digabungkan untuk mendapatkan suatu nilai strategis yang saling menguntungkan.

Apriyanti, adalah Dosen Prodi Manajemen STIE Dharma Iswara Madiun 
Aliansi bisnis muncul sebagai strategi efektif untuk menanggapi pasaran yang makin mendiversifikasi \& lingkungan yang dinamis. Dalam dunia bisnis terdapat beraneka bentuk aliansi bisnis atau kemitraan. Bahkan di negara majuseperti Jepang aliansi bisnis dianggap sebagai jalan keluar terakhir dalam strategi manajemen. Aliansi demikian juga dapat memberi kelenturan pada perusahaan - perusahaan yang mereka butuhkan untuk memperoleh jangkauan kebutuhan pasar yang semakin beraneka ragam.

Komoditas mebel kayu Jawa Tengah, telah menembus pasar di 68 negara tujuan ekspor sekaligus menjadi komoditas andalan Jawa Tengah. Selama kurun waktu 2009 - 2013ekspor non migas Jawa tengah menunjukkan kinerja cukup baik. Laju pertumbuhan ekspor mencapai rata-rata $19,64 \%$ per tahun dengan devisa naik dan 843,87 juta dollar pada tahun 2009 menjadi 1.551,06 juta dollar pada tahun 2010. Diharapkan kinerja ekspor dapat dipertahankan \& ditingkatkan melalui efisiensi \& peningkatan kualitas produk, agar memiliki daya saing tinggi untuk menembus pasar global. Apalagi ekspor meubel akan tetap menjadi tumpuan harapan bagi perolehan devisa, sekaligus membuka peluang kerja.

Penurunan nilai ini impor terutama karena adanya penurunan dalam impor kelompok barang modal yang mengalami penurunan sebesar USD 312 juta atau $70,48 \%$ dari posisi yang sama pada tahun 2013. Dampak dari krisis ekonomi nampaknya masih berpengaruh terhadap minat investor untuk melakukan ekspansi dalam kegiatan usahanya, sehingga permintaan akan barang modal untuk kebutuhan industri mengalami penurunan yang cukup tinggi.

Porsi komoditi export non migas terbesar Propinsi Jawa Tengah adalah perabot rumah dan barang dari kayu yang tercatat sebesar USD.497 juta atau 28,65\% dari total export non migas Jawa Tengah. Komoditi ini mengalami kenaikan yang menguntungkan, yaitu sebesar 69,44\% dibandingkan dengan realisasi export pada tahun sebelumnya sebesar USD 293 juta.

Pasar furniture ukir Jepara makin diminati konsumen manca negara, sehingga aktivitas volume export terlihat terus meningkat. Demikian pula yang dihadapi beberapa perusahaan meubel yang ada di Kabupaten Jepara. Seiring dengan meningkatnya volume export, ada beberapa kendala yang sedikit berdampak terhadap kelangsungan hidup perusahaan.

Permasalahan yang dihadapi para pengusaha furniture adalah keterbatasan kapasitas produksi dan keterbatasan design yang dimiliki. Sehingga produsen tidak mampu memenuhi permintaan tertentu, baik jumlah maupun design yang dipesan. Hal ini tidak mungkin dipenuhi / dicarikan solusinya oleh perusahaan dalam jangka waktu yang relatif cepat .Oleh karena itu dapat diantisipasi dengan melalukan strategi aliansi antar beberapa perusahaan, sehingga antara perusahaan dapat saling menjalin kerjasama dalam memenuhi order dan para buyer yang selalu berfluktuasi baik jumlah produk maupun designnya.

Berdasarkan latar belakangpermasalahan tersebut, maka untukmenghindari terjadinya keadaan ini rumusan permasalahan yang hendak dianalisa adalah:

1) Bagaimana perusahaan-perusahaan tersebut diarahkan untuk melakukan strategi aliansi, sehingga mampu menghadapi pasar global, dengan menganalisis faktor ekstern dan faktor internnya. 
2) Alternatif strategi aliansi apa yang dapat dikembangkan oleh masing-masing perusahaan agar dapat mengoptimalkan kegiatan operasionalnya.

\section{TINJAUAN PUSTAKA}

\section{Pengertian Aliansi}

Aliansi strategis mengaitkan mata rantai aspek bisnis tertentu antara 2 atau lebih perusahaan. Menurut Hamsal (1997) keterkaitan bisnis yang dimaksudkan untuk meningkatkan efektifitas strategi bersaing dari masing-masing perusahaan yang terlibat didalamnya dalam rangka meraih keuntungan bersama. Konsep yang melandasi aliansi adalah : suatu cara untuk menggerakkan (generate) dampak sinergistik dalam manajemen sumberdaya bisnis dengan menjalankan operasi diversifikasi dalam lingkungan bisnis yang sudah ada.

Prinsip-prinsip yang mendasari suatu bentuk perusahaan aliansi adalah :

a. Masing-masing pihak yang beraliansi dapat membagi keuntungan dan resiko (shared) terhadap hasil aliansi melalui pengendalian kinerja opersi yang disepakati (Dadan, 1996; Hamsal, 1997).

b. Hubungan kerjasama dalam aliansi strategis hams didasarkan atas kerjasama yang berkesinambungan, dengan prinsip mempertukarkan atau mengintegrasikan pada satu atau lebih yang tidak pokok seperti teknologi, produk dan jasa, ketrampilan tertentu serta akses pasar (Yoshino \& Rangan 1995; Hamsal 1997).

\section{Bentuk Aliansi} kontrak yaitu :

Menurut Dadan (1996), dalam aliansi non tradisional ini dikenal 2 bentuk

a. Kontrak kerjasama Manajemen (joint of management), yaitu : kontrak yang ditawarkan satu badan usaha kepada pihak yang lain untuk secara bersamasama mengelola satu usaha yang dimiliki.

b. Kontrak kerjasama Operasi (joint of operation), yaitu bentuk kontrak yang ditawarkan oleh satu badan usaha kepada pihak lain untuk secara bersama - sama menanamkan modalnya dalam salah satu usaha yang dimilikinya.

Strategi aliansi yang efektif dapat berlangsung apabila perusahaan yang terlibat di dalamnya mengembangkan mekanisme struktur, proses dan ketrampilan yang dimiliki dapat menjembatani perbedaan dan mengatasi kendala organisasional dan memperoleh value creation (membuahkanbasil bersama) yang sama - sama diperlukan. Tujuan utama aliansi strategik adalah : memungkinkan suatu perusahaan/grup untuk mencapai tujuan tertentu yang tidak dapat dicapai dengan usaha sendiri (Dicken, 1992 : h. 213-15).

\section{Syarat Aliansi}

Kanter (1994) mengungkapkan paling tidak ada aspek mendasar yang juga merupakan prasyarat utama untuk terwujudnya aliansi bisnis.

a. Aliansi harus mampu menghasilkan bagi setiap partner dan bukan hanya sekedardeal bisnis semata.

b. Keberhasilan aliansi bisnis akan banyak bertumpu pada rasa kesatuan dan 
kebersamaan (collaboration) melalui proses penciptaan nilai bersamasama,bukan hanya sekedar proses pertukaran (exchange) atas sejumlah nilai investasi tertentu.

c. Aliansi yang terbentuk tidak dapat sepenuhnya dikendalikan oleh sistem formal yang ada.

Menurut Casares (1994), dalam artikelnya di Harvard Bussines Review : "Group versus Group, How Alliance Networks complete", dengan networks alliances, ada 3 keunggulan utama yang dapat diperoleh :

a. Pertama, persaingan antar jaringan terjadi didalam technical standard.

b. Kedua, dengan meningkatnya global scale akan menciptakan suatu lahan yang subur bagi jaringan aliansi.

c. Ketiga, teknologi baru menciptakan hubungan antar industri yang dulunya terpisah.

\section{Tujuan Aliansi}

Yoshino \& Rangan (1995) serta Krannert mendefinisikan aliansi strategis secara lebih formal sebagai suatu kerjasama bisnis yang saling menguntungkan antara dua atau lebih perusahaan dalam rangka meningkatkan efektivitas strategi persaingan (Competitive advantage) dari masing-masing perusahaan tersebut. Tiga ciri utama dari aliansi strategis sebagai berikut :

a. Aliansi strategis memiliki tujuan yang disepakati bersama oleh seluruh perusahaan anggota aliansi strategis.

b. Perusahaan aliansi strategis tidak hanya membagi manfaat (benefit tetapi juga membagi kendali (control) atas kinerja (performance) aliansi strategis.

c. Perusahaan anggota aliansi strategis memberikan sumbangan (contribution) secara berkesinambungan/berkelanjutan pada satu atau lebih bidang kunci (key area) dari aliansi strategis.

\section{METODE}

\section{Populasi dan teknik pengambilan sampel}

Populasi yang digunakan sebagai sample frame adalah seluruh perusahaan besar yang ada di Kabupaten Jepara. Sample yang dipilih secara purposive dengan ketentuan sebagai berikut:

1. Perusahaan harus memiliki spesifikasi produk tertentu

2. Perusahaan belum pemah menjalin kerjasama dengan perusahaan lain

3. Perusahaan bukan milik warga negara asing

Pada penelitian ini populasi dan sampel digunakan untuk mendapatkan data primer untuk penentuan nilai bobot faktor-faktor stratejik internal (kekuatan dan kelemahan) dan penentuan nilai bobot faktor stratejik Eksternal (peluang \&ancaman).Yang menjadi populasi adalah perusahaan yang memiliki syarat-syarat tersebut berjumlah 55 perusahaan.

Sedang untuk menentukan ukuran sampel digunakan rumus stovin \& sevilla (1994) yang dikutip oleh Husein Umar (1999) 


$$
n=\frac{N}{1+N \boldsymbol{\square} e \%}
$$

$$
\begin{array}{ll}
\mathrm{N} & =\text { ukuran Sample } \\
\mathrm{n} & =\text { Ukuran populasi } \\
\mathrm{e} & =\% \text { kelonggaran ketidaktelitian karena kesalahan pengambilan } \\
& \text { sample yang masih ditolerir. }
\end{array}
$$

Tentang pemakaian rumus tersebut Paquso, Garsia, Gurero (1978) yang dikutip oleh Umar (1999) memperlihatkan bahwa batas kesalahan (nilai e) berkisar $1 \%-10 \%$. Semakin kecil ukuran populasi, nilai e lebih besar. Dengan $\mathrm{e}=3 \%$ dan memasukkan persamaan Slovin didapatkan sampel sebanyak 20. Hal ini digunakan sebagai dasar pengambilan sample.

\section{Metode Pengumpulan Data}

Untuk mencapai tujuan penelitian maka dilakukan penelitian survey dari satu populasi dengan menggunakan kuesioner sebagai alat pengumpul data primer serta data - data yang diperoleh dari perusahaan sebagai data sekunder yang dikumpulkan melalui wawancara bebas.

\section{Teknik Analisis}

\section{1) Identifikasi Faktor - faktor Internal dan Eksternal}

Dengan membuat matrik faktor strategi eksternal, untuk mengetahui terlebih dahulu faktor strategi eksternal (External Strategic Factors Analysis Summary).

Melalui matrik SWOT dapat dipetakan bagaimana bidang-bidang usaha hasrus di KSU kan serta mana yang seharusnya dikerjakan sendiri. Menurut Aaker, David A (1995) yang dikutip Dadan Umar (1997) secara rinci menyebutkan bahwa bidang- bidang tersebut pada tabel berikut.

Tabel 1

Matrik SWOT

\begin{tabular}{|c|c|c|}
\hline IFE & $\begin{array}{c}\text { Peluang } \\
\text { (OPPURTUNITY) }\end{array}$ & $\begin{array}{c}\text { Ancaman } \\
\text { ( THREATS ) }\end{array}$ \\
\hline Kekuatan & SO & ST \\
( STRENGHTS $)$ & Internal Actvity & (Complementary \\
\hline Kelemahan & WO & WT \\
(WEAKNESS) & Complementary Alliances & (Diserved/ consolidations ) \\
\hline
\end{tabular}

Sumber :Aaker, David A (1995) Dalam dadan Umar (1997).

\section{2) Matrik BCG}

Metode pendekatan untuk tujuan penelitian yang kedua, digunakan teknik analisis korporat yaitu BCG Growth / Share matrix. Teknik ini bertujuan untuk: mengembangkan strategi pangsa pasar, mengembangkan portofolio produk perusahaan sehingga jelas kekuatan dan kelemahannya, 
mengalokasikan anggaran pemasaran produk guna memaksimalkan cash flow jangka panjang, serta mengukur kinerja manajemen berdasarkan kinerja produk dipasaran.

Tabel 2

BCG's Growth Share Matrix

POSISI KOMPETETIF RELATIF (MARKET SHARE)

\begin{tabular}{|c|c|c|c|}
\hline \multirow{2}{*}{\multicolumn{2}{|c|}{ MARKET SEGMENT High }} & High & Low \\
\hline & & STAR & QUESTION MARK \\
\hline (persen) & Low & CASH COW & DOGS \\
\hline
\end{tabular}

Sumber : Hasil Analisis

Freddy Rangkuti, “Analisis SWOT Teknik Membedah Kasus Bisnis"

Jakarta Gramedia Pustaka Utama 1999.

\section{3) Quantitative Strategic Planning Matrix}

Analisis ini berusaha untuk mengintegrasikan factor ekstemal dan internal ke arah penentuan strategi yang terbaik, tanpa melihat terlalu tinggi ataupun terlalu rendah strategi yang akan diambil.

\section{PEMBAHASAN}

\section{GAMBARAN UMUM OBYEK PENELITIAN}

Pemilihan lokasi dilakukan secara purposive yaitu pemilihan dilakukan searah dengan tujuan tertentu. Obyek penelitian yang dipilih adalah adalah perusahaan - perusahaan domestik yang memiliki spesifikasi produk tertentu. Alasan pemilihan lokasi ini karena sesuai dengan obyek penelitian, dimana perusahaan yang digunakan sebagai sample melakukan eksport ke manca negara sehingga sesuai dengan sasaran riset.

\section{Tabel 3}

Perusahaan Furniture Di Kabupaten Jepara Dengan Spesifikasi Produknya

\begin{tabular}{|ll|l|}
\hline \multicolumn{2}{|c|}{ Nama Perusahaan } & \multicolumn{1}{c|}{ Spesifikasi Model \& Produk } \\
\hline 1. & ABDI JATI & Indoor Outdor Furniture \\
2. & ANTIQUE INDAH & Classic Furniture \\
3. & ASRI & Indoor Outdoor Furniture \\
4. & BUMI JEPARA & Clasic Furniture \\
\hline 5. & CLASSIC FURNITURE & Garden Furniture \\
6. & DUTA JEPARA & Garden Furniture \\
\hline
\end{tabular}




\begin{tabular}{|c|c|}
\hline Nama Perusahaan & Spesifikasi Model \& Produk \\
\hline $\begin{array}{ll}7 . & \text { EDY'S ABADI } \\
\text { 8. } & \text { HANSE GARDEN INDONESIA } \\
\text { 9. } & \text { ISTANA MEBEL } \\
\end{array}$ & $\begin{array}{l}\text { Indoor Outdoor Furniture } \\
\text { Garden \&Assesories Furniture } \\
\text { Indoor Outdoor Furniture }\end{array}$ \\
\hline $\begin{array}{l}\text { 10. JATI MAKMUR AGUNG } \\
\text { 11. KALINGGA JATI } \\
\text { 12. KARTINI } \\
\text { 13. KOTA JATI FURNITURE } \\
\text { 14. MAJAPAHIT } \\
\text { 15. MUSTIKA JATI } \\
\text { 16. PUTRA AULIA } \\
\text { 17. QUEEN FURNITURE } \\
\text { 18. } \text { RAHMATIKA } \\
\text { 19. SANGGAR JATI } \\
\text { 20. SATIN ABADI }\end{array}$ & $\begin{array}{l}\text { Clasic Furniture } \\
\text { Indoor Outdoor Furniture } \\
\text { Clasic Furniture } \\
\text { Clasic Furniture } \\
\text { Relief } \\
\text { Indoor Outdoor Furniture } \\
\text { Garden Furniture } \\
\text { Garden Furniture } \\
\text { Souvenir } \\
\text { Clasic Furniture } \\
\text { Indoor Outdoor Furniture }\end{array}$ \\
\hline
\end{tabular}

Sumber : Data ASMINDO Kabupaten Jepara

Dari sekian banyak perusahaan yang ada di Kabupaten Jepara ini khususnya dengan spesifikasi produk masing- masing, yang sesuai dengan sample yang dipilih sebanyak 20 perusahaan. Namun setelah dianalisa ternyata hanya 4 perusahaan yang benar- benar memenuhi syarat untuk dapat melakukan strategi aliansi. Berikut data produksi masing - masing perusahaan dalam 3 tahun terakhir:

Tabel 4

Data Produksi Masing-masing Perusahaan 2010 - 2013 (dalam unit)

\begin{tabular}{|l|c|c|c|c|c|}
\hline \multicolumn{1}{|c|}{ Nama Perusahaan } & $\begin{array}{c}\text { Tahun } \\
2010\end{array}$ & $\begin{array}{c}\text { Tahun } \\
2011\end{array}$ & $\begin{array}{c}\text { Tahun } \\
2012\end{array}$ & $\begin{array}{c}\text { Tahun } \\
2013\end{array}$ & $\begin{array}{c}\text { Rata-rata } \\
\text { Produksi /th }\end{array}$ \\
\hline 1. ASRI JEPARA & 159.151 & 160.885 & 163.418 & 161.814 & 161.317 \\
2. DUTA JEPARA & 168.831 & 170.193 & 172.172 & 173.941 & 171.284 \\
3. HANSE GARDEN INDONESIA & 155.163 & 157.096 & 159.246 & 155.239 & 156.686 \\
4. KOTA JATI FURNITURE & 159.317 & 163.582 & 168.414 & 169.951 & 165.316 \\
\hline
\end{tabular}

Sumber : data primer diolah

\section{Marketing Mix}

a. Product

Untuk melakukan kegiatan produksi Furniture, selain berdasarkan atas pesanan sebagian besar merupakan pengembangan dari produk yang pernah dipesan dengan inovasi tertentu, serta meklakukan produksi massal guna dijual di pasaran umum. Bahan baku yang dipergunakan berbagai jenius kayu (jati, mahoni, rami), disamping bahan - bahan lainnya (busa, kain, lem, plitur, cat). Bahan kayu merupakan komponen biaya yang paling besar disbanding komponen lainnya. Bahan kayu tersebut diperoleh melalui pemasok ataupun langsung ke produsennya. 


\section{b. Price}

Dengan memperhatikan kegiatan yang dilaksanakan maka terdapat variasi harga yang sangat bervariatif dari masing - masing perusahaan. Harga ditetapkan berdasarkan kalkulasi biaya produksi, ditambah biaya pemasaran, dan keuntungan yang diharapkan. Dari kalkulasi harga ini kemudian ditawarkan kepada calon pembeli.

\section{c. Promotion}

Dalam melakukan promosi antara lain : melalui pameran dagang di dalam negeri. Disamping itu juga melakukan kunjungan dan melihat pameran dagang di Luar Negeri.Dengan beberapa pengalaman mengikuti pameran dan kunjungan dagang ini banyak dirasakan manfaatnya terhadap penjualan furniture. Manfaat ini antara lain berupa meningkatnya order dan transaksi penjualan dengan buyer asing.

\section{d. Distribution}

Dilihat distribusi pemasarannnya sebagian besar produk diarahkan untuk pasar export dengan 68 negara tujuan, termasuk Amerika dan Belanda. Sedangkan tujuan export mebel terbesar saat ini adalah Jepang, disusul Amerika Serikat. Dalam melakukan pemasaran para pengusaha bekerja sama dengan pembeli pembeli dan luar negeri baik berhubungan secara langsung maupun tidak langsung (melalui broker).

Hasil penelitian yang merupakan hasil pengolahan data yang diperoleh di lapangan, baik dilakukan dengan observasi ataupun data - data yang diperoleh dan jawaban kuesioner. Hasil penelitian ini diarahkan untuk mengetahui kebijakan strategi yang telah dilakukan, yaitu berupa strategi aliansi.

Berdasarkan hasil analisis diharapkan dapat diperoleh jawaban tentang permasalahan yang dihadapi oleh para pengusaha dalam melakukan strategi aliansi khususnya dalam menghadapi persaingan bebas.

\section{ANALISIS FAKTOR EKSTERNAL \& INTERNAL}

Untuk melakukan analisis faktor ini dilakukan dengan analisis factor external dan factor internal. Meliputi penentuan factor yang digolongkan dalam 2 variabel yaitu : variable peluang dan variable ancaman. Hasil identifikasi masing masing variabel external \& variabel internal adalah seperti tabel di bawah ini : 
Tabel 5

Hasil Analisis Matrik Ifas Dan Matrik Efas Pada 4 Perusahaan Furniture

\begin{tabular}{|c|c|c|c|c|c|c|c|c|c|}
\hline \multirow[t]{2}{*}{ Internal Factor Analysis Summary } & \multirow[t]{2}{*}{ BOBOT } & \multicolumn{2}{|c|}{ ASRI JEPARA } & \multicolumn{2}{|c|}{ DUTA JEPARA } & \multicolumn{2}{|c|}{$\begin{array}{l}\text { HANSE } \\
\text { GARDEN }\end{array}$} & \multicolumn{2}{|c|}{ KOTA JATI } \\
\hline & & RATING & NILAI & RATING & NILAI & RATING & NILAI & RATING & NILAI \\
\hline \multicolumn{10}{|l|}{ STRENGTH (Kekuatan) } \\
\hline 1. Fasilitas produksi berteknologi tinggi & 010 & 3 & 0,30 & 2 & 0,20 & 2 & 0,20 & 3 & 0,30 \\
\hline 2. Flexibilitas design & 0,11 & 4 & 0,44 & 4 & 0,44 & 3 & 0,33 & 3 & 0,33 \\
\hline 3. Jalinan kerjasama dengan perusahaa lain & 0,11 & 3 & 0,33 & 4 & 0,44 & 4 & 0,44 & 2 & 0,22 \\
\hline 4. Manajemen yang terkoordinasi & 0,10 & 4 & 0,40 & 2 & 0,20 & 3 & 0,30 & 4 & 0,40 \\
\hline 5. Pangsa pasar yang luas & 0,09 & 3 & 0,27 & 3 & 0,27 & 4 & 0,36 & 4 & 0,36 \\
\hline \multicolumn{10}{|l|}{ WEAKNESS (Kelemahan) } \\
\hline 1. Terbatasnta design yang tersedia & 0,09 & 4 & 0,36 & 4 & 0,36 & 3 & 0,27 & 4 & 0,36 \\
\hline 2. Respon layman puma jual kurang baik & 0,10 & 2 & 0,20 & 2 & 0,20 & 2 & 0,20 & 3 & 0,30 \\
\hline 3. Kurangnya tenaga ahli & 0,11 & 3 & 0,33 & 3 & 0,33 & 3 & 0,33 & 4 & 0,44 \\
\hline 4. Promosi kurang intensif & 0,10 & 4 & 0,40 & 4 & 0,40 & 2 & 0,20 & 4 & 0,40 \\
\hline 5. Promosi kurang intensif & 0,09 & 2 & 0,18 & 3 & 0,27 & 3 & 0,27 & 2 & 0,18 \\
\hline TOTAL NILAI PEMBOBOTAN & 100 & & 3,15 & & 3,11 & & 2,90 & & 3,29 \\
\hline \multirow{2}{*}{\multicolumn{10}{|c|}{$\begin{array}{lrl}\text { Eksternal } & \text { Factor } & \text { Analysis } \\
\text { Opportunity (Peluang) } & \end{array}$}} \\
\hline & & & & & & & & & \\
\hline 1. Kebijakan pemerintah & 0,10 & 4 & 0,40 & 3 & 0,30 & 4 & 0,40 & 4 & 0,40 \\
\hline 2. Pajak eksport & 0,09 & 3 & 0,27 & 4 & 0,36 & 3 & 0,27 & 3 & 0,27 \\
\hline 3. Banyaknya perajin yang dimiliki & 0,11 & 3 & 0,33 & 4 & 0,44 & 2 & 0,22 & 4 & 0,44 \\
\hline 4. Keunggulan produk khusus & 0,12 & 4 & 0,48 & 4 & 0,48 & 1 & 0,24 & 3 & 0,36 \\
\hline 5. Kebijaksaan harga & 0,10 & 3 & 0,30 & 3 & 0,30 & 3 & 0,30 & 4 & 0,40 \\
\hline \multicolumn{10}{|l|}{ THREAT (Ancaman) } \\
\hline 1. Persaingan yang ketat & 0,09 & 4 & 0,36 & 4 & 0,36 & 4 & 0,36 & 3 & 0,27 \\
\hline 2. Kemajuan teknologi & 0,11 & 3 & 0,33 & 3 & 0,33 & 4 & 0,44 & 4 & 0,44 \\
\hline 3. Adanya pesaing asing & 0,11 & 4 & 0,44 & 2 & 0,22 & 3 & 0,33 & 4 & 0,44 \\
\hline 4. Complain pengiriman dari buyer & 0,08 & 2 & 0,24 & 4 & 0,32 & 3 & 0,24 & 4 & 0,32 \\
\hline 5. Kualitas tenaga ahli minim & 0,09 & 3 & 0,27 & 2 & 0,18 & 3 & 0,27 & 3 & 0,27 \\
\hline TOTAL NILAI PEMBOBOTAN & 100 & & 3,29 & & 3,29 & & 2,97 & & 3,21 \\
\hline
\end{tabular}




\section{ANALISIS SWOT MATRIX}

Analisis SWOT Matrix merupakan analisis untuk menghasilkan alternatif strategi yang akan digunakan oleh perusahaan. Analisis ini menggambarkan peluang dan ancaman ekternal yang dipasangkandengan kekuatan dan kelemahan yang ada dalam perusahaan.

\section{Tabel 6}

Analisis Matrik Swot

\begin{tabular}{|c|c|c|}
\hline & STRENGTH & WEAKNESS \\
\hline $\begin{array}{l}\text { External Factor } \\
\text { Analysis summary }\end{array}$ & $\begin{array}{l}\text { 1. Fasilitas Produksi } \\
\text { berteknologi tinggi. } \\
\text { 2. Flexibilitas design } \\
\text { 3. Jalinan kerjasama } \\
\text { dengan perusahaan lain } \\
\text { 4. Manajemen yang } \\
\text { terkoordinasi } \\
\text { 5. Pangsa pasar yang luas }\end{array}$ & $\begin{array}{ll}\text { 1. } & \text { Terbatasnya design yang } \\
& \text { dimiliki } \\
\text { 2. } & \text { Respon layanan puma jual } \\
\text { kurang baik } \\
\text { 3. } \\
\text { 4. } \text { Terangnya tenaga ahli } \\
\text { fasilitasnya kelengkapan } \\
\text { 5. } & \text { Promosi kurang intensif }\end{array}$ \\
\hline OPPORTUNITY & STRATEGI SO & STRATEGI WO \\
\hline $\begin{array}{l}\text { 1. Kebijakan pemerintah } \\
\text { 2. Pajak export } \\
\text { 3. Kuantitas perajin cukup } \\
\text { besar } \\
\text { 4. Keunggulan produk } \\
\text { khusus } \\
\text { 5. Kebijaksanaan harga }\end{array}$ & $\begin{array}{l}\text { 1. Meningkatkan kualitas } \\
\text { kinerja perusahaan yang } \\
\text { lebih baik. } \\
\text { 2. Menetapkan strategi harga } \\
\text { 3. Perluasan pangsa } \\
\text { pasar } \\
\text { 4. Mempertahankan } \\
\text { market leader }\end{array}$ & $\begin{array}{l}\text { 1. Mengembangkan system } \\
\text { informasi untuk } \\
\text { mempermudah proses } \\
\text { produksi, integrasi design, } \\
\text { \& after sales service } \\
\text { 2. Meningkatkan efisiensi } \\
\text { jaringan distribusi } \\
\text { 3. Pengembangan SDM }\end{array}$ \\
\hline THREAT & STRATEGI ST & STRATEGI WT \\
\hline $\begin{array}{l}\text { 1. Persaingan lokal yang } \\
\text { ketat } \\
\text { 2. Kemauan teknologi } \\
\text { 3. Adanya pesaing asing } \\
\text { 4. Complain pengiriman dari } \\
\text { buyer } \\
\text { 5. Kualitas tenaga ahli masih } \\
\text { minim }\end{array}$ & $\begin{array}{l}\text { 1. Efisiensi produk dengan } \\
\text { menggunakan fasilitas yang } \\
\text { lebih baik sesuai kemajuan } \\
\text { teknologi. } \\
\text { 2. Memperbaiki system } \\
\text { pengiriman barang dengan } \\
\text { menjalin kerjasama antar } \\
\text { peusahaan asingn maupun } \\
\text { domestik. } \\
\text { 3. Peningkatan mutu SDM } \\
\text { agar capable \& memiliki } \\
\text { pengetahuan industri } \\
\text { furniture }\end{array}$ & $\begin{array}{l}\text { 1. Mengadakan pameran skala } \\
\text { besar \& frekwensi tinggi } \\
\text { dengan proiritas pengenalan } \\
\text { produk \& penjelasan } \\
\text { keunggulan produk secara } \\
\text { professional. } \\
\text { 2. Mengembangkan design } \\
\text { yang sudah ada serta } \\
\text { mampu mengikuti trend } \\
\text { sehingga buyer lebih mudah } \\
\text { untuk melakukan order } \\
\text { tanpa hambatan }\end{array}$ \\
\hline
\end{tabular}

Sumber : data primer diolah 


\section{Tabel 7}

Data Hasil Penjualan Produk

Tahun 2011 - 2013 ( Dlm ribuan Rp)

\begin{tabular}{|c|c|c|c|}
\hline Nama Perusahaan & Tahun 2011 & Tahun 2012 & Tahun 2013 \\
\hline 1. ASRI JEPARA & 139.181.241 & 148.426 .223 & 100.894 .045 \\
\hline 2. DUTA JEPARA & 159.491 .739 & 164.418 .973 & 160.232 .814 \\
\hline 3. HANSE GARDEN IND & 119.739 .468 & 120.051 .067 & 121.566 .105 \\
\hline $\begin{array}{l}\text { 4. KOTAJATI } \\
\text { FURNITURE }\end{array}$ & 140.090 .732 & 139.360 .052 & 133.562 .972 \\
\hline TOT A L & 558.603 .140 & 572.256 .269 & 516.255 .936 \\
\hline
\end{tabular}

Sumber : Data Primer Diolah

a. Perhitungan Pangsa Pasar Relatif ( MSR )

MSR adalah perbandingan antara besarnya penjualan yang dapat dikuasai suatu perusahaan dengan penjualan yang dikuasai pesaing dominan atau pesaing terbesar. Besarnya MSR ini berwujud angka mutlak, nilainya bisa = $1,<1$ atau $>1$, dengan rumus:

$$
M S R=\frac{\text { Penjualan Tahun } n}{\text { Penjualan Pesaing dominan Tahun } n}=\cdots \ldots \ldots \ldots \ldots
$$

dari tabel diatas dapat dihitung besarnya MSR tahun 2012 untuk masingmasing perusahaan, sebagai berikut :

$$
\begin{aligned}
& \text { 1) Duta Jepara }=\frac{160.232 .814}{100.894 .045}=1,5 \\
& \text { 2) Asri Jepara }=\frac{100.894 .045}{160.232 .814}=0,62 \\
& \text { 3) } \text { Hanse Garden }=\frac{121 \cdot 566 \cdot 105}{160 \cdot 232.814}=0,75 \\
& \text { 4) } \text { Kota Jatie } \quad=\frac{133.562 .972}{160.232 .814}=0,83
\end{aligned}
$$

dari hasil perhitungan tersebut maka pangsa pasar (MSR) untuk ketiga perusahaan (ASRI JEPARA, HANSE GARDEN, KOTA JATIE) adalah $<$ dari 1 ini berarti : Perusahaan - perusahaan itu memiliki pangsa pasar lebih kecil dari kompetitor utama.

Sedangkan untuk DUTA JEPARA sebesar 1,5 x, artinya perusahaan ini memiliki pangsa pasar lebih besar dari kompetitor utama.

b. Perhitungan tingkat pertumbuhan pasar (MGR)

Tingkat pertumbuhan industri dihitung dari pertumbuhan penjualan perusahaan yang diteliti dibandingkan dengan penjualan dari industrinya. Tingkat pertumbuhan industri dapat dirumuskan sebagai berikut : 


$$
M G R=\frac{M 1-M 2}{M 2} \times 100 \%
$$

Keterangan :

$\begin{array}{ll}\text { MGR } & \text { tingkat pertumbuhan pasar } \\ \text { M1 } & =\text { Penjualan industri tahun } \mathrm{n} \text { yang bersangkutan } \\ \text { M2 } & =\text { Penjualan industri tahun sebelumnya }\end{array}$

Dari tabel diatas maka dapat dilihat tingkat pertumbuhan pasar pada masing - masing perusahaan sebagai berikut :

1) ASRI JEPARA $=\frac{100.894 .045-148.426 .223}{148.426 .223} X 100 \%=32 \%$

2) DUTA JEPARA $=\frac{160.232 .814-164.418 .973}{164.418 .973} X 100 \%=2,5 \%$

3) $H A N S E G A R D E N=\frac{121.566 .105-120.051 .067}{120.051 .067} \times 100 \%=1,2 \%$

4) KOTA JATIE $=\frac{133.562 .972-139.360 .052}{139.360 .052} \times 100 \%=4,1 \%$

Sehingga dari perhitungan tersebut dapat ditentukan bahwa tingkat pertumbuhan pasar (MGR) untuk ke 3 perusahaan (KOTA JATIE, DUTA JEPARA \& HANSE GARDEN) MGR-nya $<10 \%$, maka tingkat pertumbuhan pangsa pasarnya relaif rendah.

Sedangkan pada ASRI JEPARA sangat tinggi yaitu $>10 \%$. Dari tingkat pertumbuhan pangsa pasar yang relatif tinggi maka akan mendorong munculnya pesaing-pesaing baru. Pada MGR 1 perusahaan yang sangat tinggi itu $(>10 \%)$ menunjukkan usaha yang berada pada posisi ini memiliki peluang untuk penetrasi pasar yang besar, karena tingginya pertumbuhan pasar. Pada pasar yang sedang tumbuh. Pertumbuhan pasar sangat mudah dicapai dibandingkan dengan pasar yang tidak berkembang. Tetapi perusahaan belum dapat memanfaatkan peluang pasar yang ada.

Bila dilihat pada matrix BCG hasil dari perhitungan MSR \& MGR adalah sebagai berikut : 


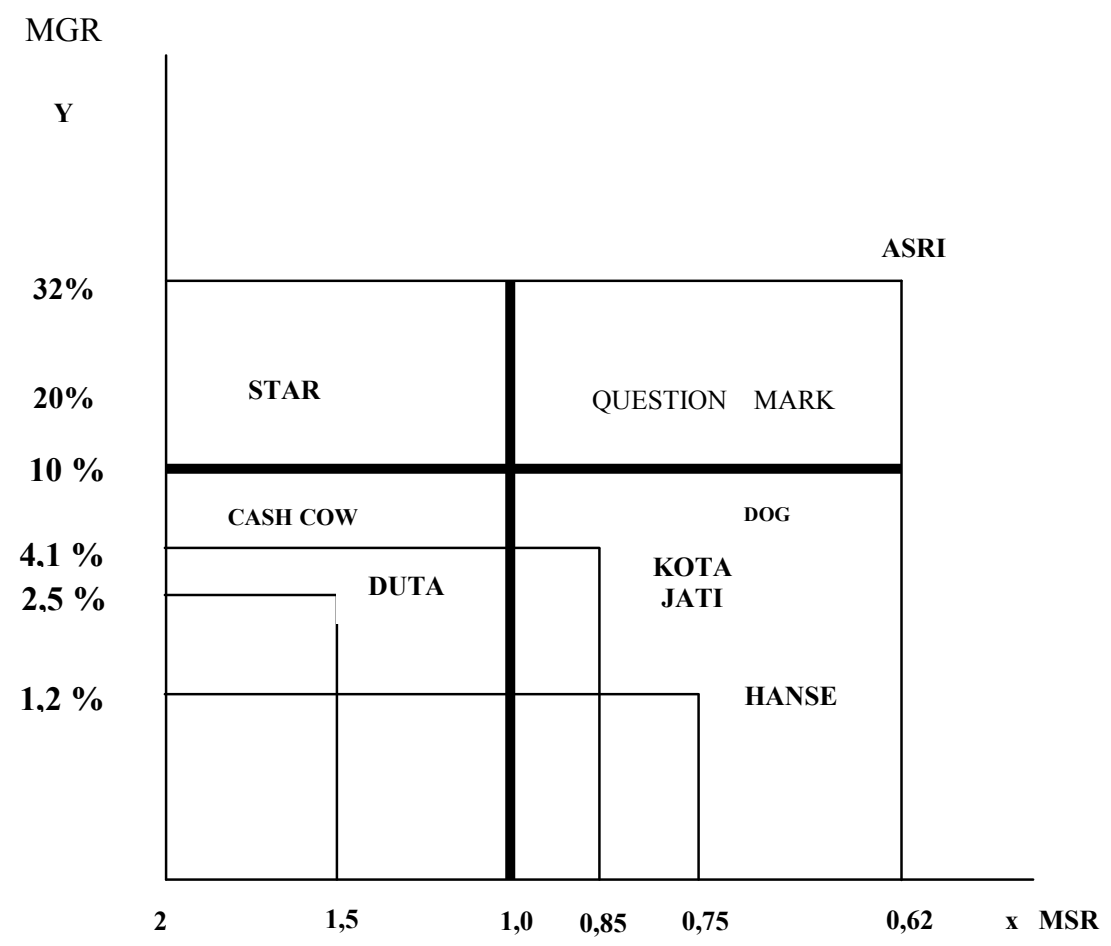

Sumber : data primer diolah

Gambar 2. Hasil Analisis Matrix BCG

1) ASRI JEPARA :

Terletak pada posisi star dimana MSR $=0,62 \times$ dari pesaing dominan, sedangkan MGR sebesar $32 \%$, ini artinya : perusahaan menghadapi pertumbuhan pasar yang sangat cepat dengan pangsa pasar yang sangat besar, sehingga diperlukan investasi untuk memperkuat posisi dominannya di dalam pasar yang sedang tumbuh.

2) DUTA JEPARA \& KOTA JATI

Kedua perusahaan ini menempati posisi Question Mark

DUTA JEPARA dengan MSR $=1,5$ dan $M G R=2,5 \%$ dan KOTA JATIMSR $=$ 0,83 dan $\mathrm{MGR}=1,2 \%$.

Pada posisi ini mempunyai ciri bergerak dalam pasar yang memiliki pertumbuhan tinggi, tetapi pangsa pasarnya relatif rendah $<1$. Kondisi ini seolah - olah memberi kesan bahwa cash flow lemah. Sementara bagian pasar mereka yang kecil membuat mereka tidak banyak menghasilkan dana. Sehingga investasi sangat diperlukan dan diharapkan dapat meningkatkan pangsa pasar dan menciptakan kondisi ke arah star. 


\section{3) HANSE GARDEN IND}

Dengan MSR $=0,75 \mathrm{X}$ MGR 1,2 \% terletak pada posisi Dog. Perusahaan dalam kondisi ini menghadapi pangsa pasar yang sngat rendah, yang terjadi pada pertumbuhan yang lamban, sehingga menunjukkan kondisi pasar yang sudahjenuh. Karena posisinya yang lemah, maka menghasilkan laba yang relatif kecil.

\section{ANALISIS QSPM MATRIX.}

Analisis ini berusaha mengintegrasikan faktor external dan internal ke arah penentuan strategi yang terbaik. Untuk dapat memilih strategi yang terbaik bagi masing-masing perusahaan digunakan alat yang berupa QSPM (Quantitative Strategic Planning Matrix). Ini dilakukan untuk mengukur alternative strategi yang paling layak untuk diterapkan.

Dan hasil QSPM dapat diketahui strategi yang paling memungkinkan untukditerapkan pada masing-masing perusahaan, sehingga nantinya dari prioritasprioritas yang dipilih, dapat terjalin kerjasama dengan perusahaan lain.

Urutan prioritas strategi tersebut adalah sebagai berikut :

1. Strategi Service (Service After Sales)

Terjadi dimana suatu kelompok organisasi dengan kebutuhan yang sama menciptakan ventura barn untuk memenuhi kebutuhan mereka (memiliki keuntungan potensial bagi kedua belah pihak).

2. Strategi Oppurtunity

Terjadi bila organisasi melihat suatu kesempatan untuk memperoleh keunggulan bersaing yang bersifat sementara. Tujuannya adalah mempergunakan peluang \& menciptakan kesempatan yang tidak akan terjadi apabila perusahaan melakukannya sendiri-sendiri.

3. Strategi Pricing Collaborations

Beberapa perusahaan bergabung dalam suatu kolaborasi untuk menentukan harga-harga khusus. Jika dikelola dengan baik suatu bentuk aliansi akan memungkinkan perusahaan memperoleh hasil penjualan yang lebih besar dengan biaya (cost) yang lebih sedikit.

4. Strategic Promotional Alliances

Kesepakatan perusahaan dalam melakukan promosi bagi produk perusahaan lainnya.

\section{KESIMPULAN}

\section{Kesimpulan}

Dari keseluruhan uraian dapat disimpulkan sebagai berikut :

1) Perusahaan - perusahaan furniture di Kabupaen Jepara dalam melakukan kegiatan operasionalnya menghadapi kendala berupa keterbatasan kapasitas produksi dan design yang dimiliki, sehingga produsen tidak mampu menienuhi order. Hal ini dapat diantisipasi dengan melakukan strategi aliansi antar perusahaan. 
2) Berdasarkan analisis faktor kekuatan dan kelemahan dari masing-masing perusahaan diketahui bahwa dari faktor kekuatan yang paling menonjol adalah fleksibili,tas design dan kemampuan menjalin kerjasama dengan perusahaan lain. Sedangkan dilihat dari faktor kelemahan yang cukup significant adalah kekurangan tenaga ahli yang dimiliki.

3) Dari hasil analisis faktor ancaman dan peluang perusahaan yang paling besar ancamannya adalah adanya pesaing asing dan kemajuan teknologi yang terus berkembang. Sedangkan faktor peluang yang mungkin dapat dipergunakan adalah masih banyaknya jumlah perajin lepas yang dimiliki perusahaan.

4) Hasil analisis SWOT Matrix diperoleh empat alternatif strategi yang dapat dikembangkan yaitu :

a. Strategi SO : dengan meningkatkan kualitas kinerja perusahaan yang lebih baik serta perluasan pangsa pasar.

b. Strategi WO : mengembangkan system informasi untuk mempermudah proses produksi, integrasi dan service after salles.

c. Strategi ST : melakukan efisiensi produksi dengan menggunakan fasilitas yang lebih baik sesuai kemajuan teknologi, serta mengembangkan design sesuai dengan selera pasar.

d. Strategi WT : mengadakan pameran dengan skala besar dan frekwensi tinggi dengan prioritas pengenalan produk dan penjelasan keunggulan produk secara professional, melalui peningkatan mutu SDM.

5) Untuk mendapatkan hasil strategi yang paling menguntungkan dan memungkinkan untuk diterapkan adalah berdasarkan hasil analisis QSP Matrix dengan urutan prioritas sebagai berikut :
a. Service Alliances
b. Oppurtunity Alliances
c. Pricing Colaborations
d. Promotional Alliances

Saran

Hasil perumusan analisis strategi aliansi perusahaan furniture atas dasar hasil analisis SWOT, BCG dan QSPM direkomendasikan 4 Strategi yang dilakukan masing - masing dengan urutan prioritas penerapan sebagai berikut :

a. Strategic Service Alliances

b. Strategic Opp Urtunity Alliances

c. Strategic Pricing Collaborations

d. Strategic Promotional Alliances

Walaupun bentuk kerjasama operasi telah diterapkan pada perusahaan furniture melalui strategi aliansi dengan baik, disarankan hal-hal sebagai berikut :

1. Dalam menjalin mitra usaha baru di kalangan perusahaan swasta haruslah dipilih yang sesuai dengan misi dan tujuan perusahaan, serta mempunyai keunggulan yang besar. Dengan menjalin kerjasama melalui:

a. Perusahaan sejenis dengan produk yang berbeda.

b. Lembaga-lembaga pengembangan SDM 
2. Meningkatkankegiatan promosi dengan melakukan pameran-pameran yang berskala besar untuk menjaring buyer sebanyak mungkin dan menjalin hubungan yang baik dengan pelanggan melalui :

a. Mencetak brosur dan menyebarluaskan pada buyer.

b. Membuat katalog produk untuk mempermudah buyer dalam melakukan order.

1) Saat melakukan pameran pada barang - barang dicantumkan harga, baik dalam \$ maupun Rp. Sehingga mempermudah pembeli dalam menentukan keputusan untuk membeli.

2) Penataan interior pameran dibuat semenarik mungkin.

3) Menyiapkan tenaga ahli yang trampil dan siap pakai dengan :

a. Merkurut tenaga kerja baru dengan pendidikan minimal kejuruan (PIKA, ATIKA, SMIK )

b. Mengembangkan SDM yang mampu menyesuaikan din dengankemajuan teknologi, khususnya finishing.

Agar strategi yang diterapkan lebih berdaya guna dan berhasil maka perludijabarkan dalam bentuk rencana kerja agar tujuan jangka panajang dan tujuan jangka pendek perusahaan dapat tercapai, perlu diadakan evaluasi keefektifan strategi setiap saat dengan menyesuaikan terhadap perubahan lingkungan perusahaan.

\section{DAFTAR PUSTAKA}

Adhiyati, Titik (2008), “Analisis Strategi aliansi Pada PT. Dharma Lautan Nusantara Cabang Semarang," Tesis program Magister Manajemen Universitas Diponegoro Semarang 1998.

Andrew, Ink Pen ( 2008 )," Learning , Knowledge, Acquisition, and Strategic Alliances," European Management Journal, Vol.16 Nov2008.

Art, Nicole (1998)," Strategic Alliances abound in Finnancial Planning Industry," Journal Trust \& Estates, Vol.138, date January, 2008.

Casseres, Benjamin Gomes (2008)," Group Versus Group: How Alliances Network Compete," Harvaed Business Review, Juli- Agustus.

Celeste, Ricard F (2005)," Strategic Alliances for Innovation: Emerging Models of Technologi Based Twenty First Century Economuc Development," Economic Develpoment Review, winter 1996.

Dadan, Umar Daihani, (2006), Aliansi Strategik, Model Dasar \& Penerapannya, Lembaga Peneliti an Tri saki, Jakarta. 
Das, TK Teng \& Bing- Sheng (2008), Between Trust and Control: " Developing Confidence In Partner Cooperation In Alliances," Journal academy Of Management Review Vol.28,July 2008.

(2009), “Managing Risk In Strategic Alliances,"Journal Academy Of Management Executive, Vol.19, Date Nov.2009.

Dicken, Peter (2012), Global Shift : The International of Economic Activity, edisi ke 2 Paul Chapman Publising Ltd, London.

Doz,Yves L (2009)," The Evaluation of Cooperation in Strategic Alliances : Initial Conditions or Learning Process? ", Strategic Management Journal, Vol. 19,2009

Frear, Carl R \& Metcalf, Lynn E (2005)," Strategic alliances and Technology Network," Industrial Marketing Management, No.25, 2005.

Freidheim, Cyrus F Jr (2009)," The Battle Of The Alliances," Journal Management Review, Vol.19Date October 2009.

Rangkuti, Ferddy (1999) ," Analisis SWOT Teknik Membedah Kasus Bisnis : Reorientasi Konsep Perencanaan Strategis untuk Menghadapi Abad 21 ,"Cetakan

Kelima September, Jakarta, PT. Gramedia Pustaka Utama.

Satyagraha, Hadi (2004," Keunggulan Bersaing dan Aliansi Strategis: Redefinisi SWOT,"Usahawan No.4 Th.XXXIII/ April, Jakarta 2004

Hamel, Gary dan Prahalad, CK (2004), "Competting For The Future," Harvard Business School Press, Boston, Massachusetts.

Utomo, Hargo (2004," Strategi Aliansi dan Persaingan Global," Usahawan No.11 Th.XXXIIINovember 2004

Elidayat ( 2004)," Aliansi Di Tengah Persaingan Global," Usahawan No.12 Th.XXXIIIDesember2004

Umar, Husein ( 2008)," Metode Penelitian Untuk Tesis Bisnis," Jakarta: Rajawali Pers. 2008.

(2009)," Riset Strategi Perusahaan," Jakarta; PT. Gramedia Pustaka

Utama,2009.

Hutt, Michael D, Stafford, Edwin R, Walker Beth A, Reingen, Peter H ( 2009)," case Study : Defining The Social Network Of A Strategic Alliances Key To Future," Journal Sloan Mana'ement Review, Vol.41 date Winter 2009. 
Kanter , Rosabeth Moss (2004)," Collaborative Advantage: The Art Of Alliance", Harvard Business Review, Juli - Agustus.

Hamsal, Mohammad ( 2007) ," Peranan Aliansi Strategis Dalam Menghadapi Persaingan Bisnis di Era globalisasi," Kelola Galah Mada University Business Review,"No.14/VI/2007, Yogyakarta.

Kuncoro, Mudrajad (2004)," Peta Bisnis Aliansi Strategik",Usahawan No.11 Th.XXXII, November.

Nagao Yoshida (2004)," Top Management Forum: Entrepreneurship for Business Alliances", Asian Productivity Organization Tokyo Japan.

Olunae Kenichi,( 2009)," The global Logic of Strategi Allince," Harvard Business Review (Ed), Global Strategic: Insights From the world's leading thinkers.

Peter Hwang, William P Burger (2007)," The Many Faces Of Multi Firm Alliances," Lesson For Manager, California Management Review, Vol.39 No.3 Spring 2007.

Saxton, Todd (2007)," The Effect of Partner and Relationship Characteristic on Alliance Out Comes," The Academy Of Management Journal Volume 40 Number 2, Pace University, Briarcliff Moror ,NY.

Sasaki, Toni ( 2008),"What Japanese Have Learned From Strategic Alliances ? ," Journal Of Long Range Planning,26,2008.

Somnath Das, Pradyot K Sen, Sanjit Sengupta (2008)," Impact Of Strategic Alliances On Firm Valuation," Academy Of Management Journal,Vol.41, No.1,2008.

Teuku Mirza ( 2006)," Aliansi Strategi Konsep Lama dan Konsep Baru", UsahawanNo.9 Th.XXXV September 2006

Thomas, Gregory A ( 2008)," Strategic Alliances Key To Future," Journal Creditunion Executive, Vol.38, date Juli/ Augustus 2008.

Wareen Mc Farlan \& Richard L. Nolan (25),"2008 How To Manage An It Outsourching Alliances" Sloan Managemant Review, Winter 2008.

Wenas, Andre Vincent (2008)," Memacu Perusahaan Lewat Aliansi Strategis," Bisnis Indonesia, 2 Januari 2008.

Yoshino, Michael \& Rangan ( 2009)," Strategic Alliances : An Entrepreneurial Approach To Globalization," Harvard Business School Pres Boston. 
146 MODERNISASI, Volume 10, Nomor 2, Juni 2014

Yoshiyo Terramoto (2009)," Entrepreneurship For Business Alliances," Graduate School Of Management, University of Tsukuba. 